
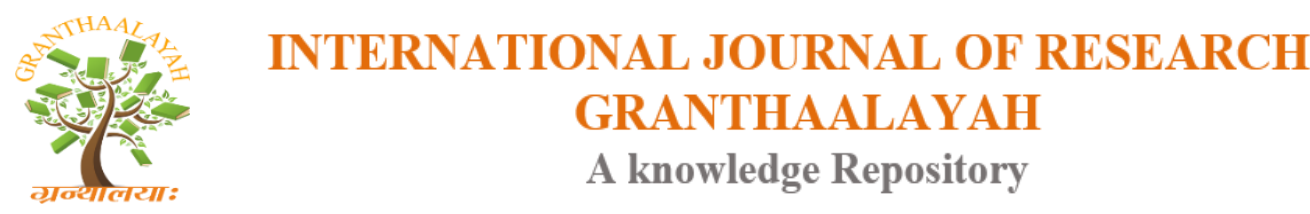

Science

\title{
THE MEASUREMENT OF HIERARCHICALLY SPATIAL INDUSTRIAL KNOWLEDGE SPILLOVER EFFECTS
}

\author{
Qianting Ye ${ }^{* 1,2}$ \\ ${ }^{* 1}$ School of Economic and Commerce, South China University of Technology, Guangzhou \\ 510006, China \\ ${ }^{2}$ School of Geographical Science and Urban Planning, Arizona State University, Tempe 85281, \\ United States
}

\begin{abstract}
Based on the "year-region-industry" three - dimensional unbalanced industrial production panel data of Guangdong Province in China from 2005-2013, the relationship between knowledge spillovers and industrial structure is investigated by hierarchically spatial lagged with spatial autoregressive error (HSARAR) model. The empirical results indicate that the impacts of MAR, Jacobs, and Porter spillover on Guangdong's industry economic growth is positive and statistically significant. The industrial HSARAR model considers the hierarchical structure and spatial effect simultaneously, which has a better description on economic reality than the pooled model and SARAR model.
\end{abstract}

Keywords: Knowledge Spillover; Hierarchically Spatial Model; GMM Estimation; Cobb -Douglas Production Function.

Cite This Article: Qianting Ye. (2018). "THE MEASUREMENT OF HIERARCHICALLY SPATIAL INDUSTRIAL KNOWLEDGE SPILLOVER EFFECTS.” International Journal of Research - Granthaalayah, 6(6), 67-74. 10.29121/granthaalayah.v6.i6.2018.1335.

\section{Introduction}

Knowledge spillover is one of the important concepts to explain agglomeration, innovation and regional growth in endogenous growth theory, new economic geography and other theoretical economic branches. Knowledge spillover becomes the important factor that affects the regional growth and innovation. It has also become an entry point for explaining spatial interaction and is one of the important reasons for industrial agglomeration. Industrial agglomeration is also conducive to the overflow and innovation of knowledge. Knowledge spillover is considered to be a very important reason for the formation of long-term competitive advantage in the industry. From a large amount of literature, it can be seen that the knowledge spillover of a real estate industry plays a key role in the industrial and economic development of the local area and even neighboring areas, especially in the areas where high-tech industries are concentrated. In the empirical analysis 
of knowledge spillovers in the existing literature, there are three different perspectives: MarshallArrow-Romer (MAR), Jacobs, and Porter spillover.

Since the beginning of the 1990s, scientists have used different econometric models based on data from different countries and different period to examine the influence of three kinds of knowledge spillovers on the growth of the industry, see Glaeser et al. (1992), Henderson et al. (1995), Cainelli and Leoncini (1999), Cainell et al. (2001), Mihn (2004), Ejermo (2005), Zhang and Wu (2008), Martin et al. (2011), Drucker (2013), and Widodo et al. (2014). In actual economy, there are differences among industries in different regions. Due to the government policies, economic conditions, geographic locations and different economic operating characteristics among regions, which will have an impact on the knowledge spillover effect among industries. Kreft and de Leeuw (1998) and Goldstein (1998) concluded that a hierarchy consists of individuals or units nested within different levels. Cliff and Ord (1973) indicated that if the existence of a certain quality of a county in a country presented more or less similarity in the neighboring counties, then this phenomenon shows spatial correlation. In other words, one ought to consider the hierarchical structure and spatial correlation in economic data.

For the purpose of establishing spatial models to recognize the unobserved hierarchical effects and spatial correlation, Corrado and Fingleton (2011, 2012) suggested the primitive structure of hierarchically spatial panel data models. Baltagi et al. (2014) applied the IV-2SLS method to estimate a hierarchically spatial lag (HSLAG) panel data model. While He and Lin (2015) extended the framework of Baltagi et al. (2014) to a SARAR model with both the spatially lagged dependent variable and the spatial autoregressive error, using MLE for estimation. Ye and Long (2016) derived the GMM-FGLS estimates for a hierarchically spatial autoregressive error (HSEAR) panel model. Then Fingleton et al. (2018) applied this approach to the house price of England. This article intends to use the HSARAR model to analyze the hierarchical effect, spatial correlation, and knowledge spillover effect.

\section{The Theoretical Model and Variables}

In terms of industrial knowledge spillover effect, numerous of researchers have been conducted according to different regions and period all over the world, they mainly focus on the issue that how knowledge spillover have an impact on industrial economic development (Lin and long, 2014). The existing literature, however, do not take account of the spatial effects and hierarchical structure among the data, causing estimation bias toward to knowledge spillover effect. GDP and its growth rate of Guangdong province are among the top ranks in China, contributing a large proportion to China's economic development. Figure 1 shows that, among 21 prefectures of Guangdong province, industry value added of 13 prefectures are lower than 15 billion Yuan, only 2 prefectures beyond 100 billion Yuan in 2005. In 2009, industry value added below 15 billion Yuan has fallen by 6 prefectures when compared to 2005, industry value added beyond 100 billion Yuan has increased to 4 prefectures. In 2013, industry value added 6 prefectures beyond 100 billion Yuan, only 1 prefecture below 15 billion Yuan. Nowadays, the scholars often use the onedimensional section or time series data, or two-dimensional balanced panel data, to investigate economic issues. However, the data they used is often "multidimensional", "incomplete" and "spatial correlated". Hence, this study employs HSARAR model and the "year-region-industry" three-dimensional unbalanced industrial production panel data set of Guangdong Province in 
China, covering 21 prefectures and 31 industries from 2005-2013, to explore the impact of knowledge spillover on industrial economic development. The data set was collected in "Guangdong Statistical Yearbook" and "Guangdong Industrial Statistics Yearbook" from 20062014. The selected 31 industrial categories refer to the classification of the national bureau of statistics (2002) with two-digit classification code. The 21 prefectures including : Guangzhou, Shaoguan, Shenzhen, Zhuhai, Shantou, Foshan, Jiangmen, Zhanjiang, Maoming, Zhaoqing, Huizhou, Meizhou, Shanwei, Heyuan, Yangjiang, Qingyuan, Dongguan, Zhongshan, Chaozhou, Jieyang, Yunfu. Each prefecture has different number of industries, they are $\{31,27,29,29,29,31,29,25,25,28,29,20,16,25,26,27,29,31,24,28,20\}$.

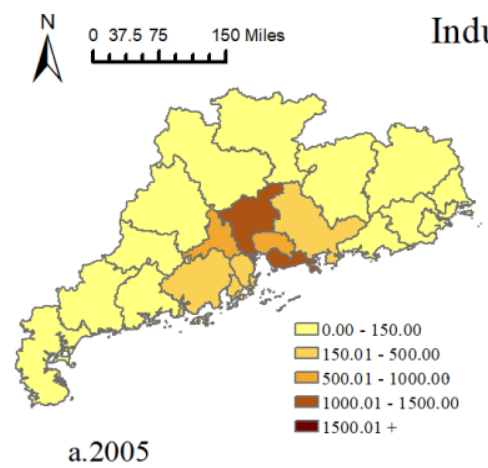

Industry Value Added/RMB 100 Million Yuan
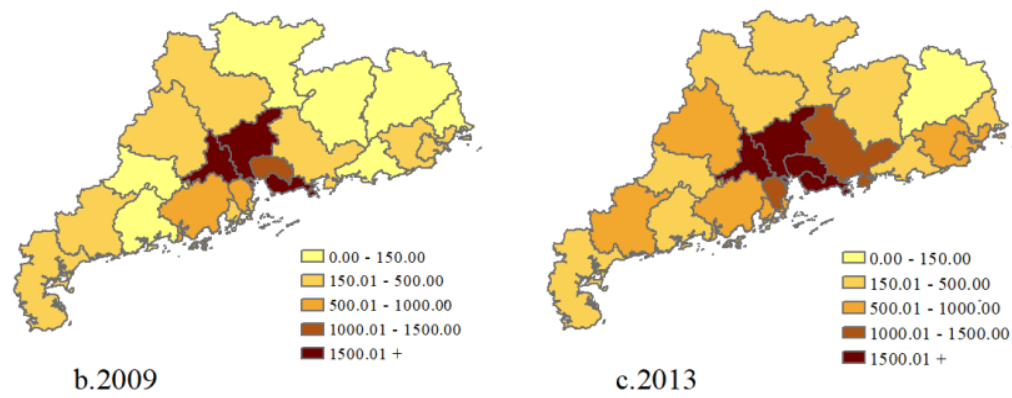

Figure 1: Industry Value Added in Guangdong Province, China (RMB 100 Million Yuan)

Considering the hierarchical structure and spatial effect of the data, we adopt Cobb-Douglas production function to discuss the impact of knowledge spillover on industrial economic development. The dependent variables are "t year- $\mathrm{i}$ region- $\mathrm{j}$ industry" of industry value added. The independent variables are technology, labor and capital inputs.

$$
y_{i j t}=A_{i j t} \cdot L_{i j t}^{\beta_{1}} \cdot K_{i j t}^{\beta_{2}}, \quad\left(i=1,2, \ldots, N ; j=1,2, \ldots, m_{i} ; t=1,2, \ldots, T\right)
$$

Where $y$ is industry value added, $A$ is technology, $L$ is labor inputs, and $K$ is capital inputs. $i$ Represents the $i$ th region, $j$ represents the $j$ th industry, $t$ represents the $t$ th time period. To avoid dimensional effects, we take the logarithmic form of equation (1) and get

$$
\ln y_{i j t}=\ln A_{i j t}+\beta_{1} \ln L_{i j t}+\beta_{2} \ln K_{i j t}+\varepsilon_{i j t}
$$

To decompose technology $A$, we have three spillover indicators: MAR spillover (specialized industry that focuses on a particular type of production can promote economic growth in that region). Jacobs spillover (diversification industrial structure in geographical proximity can promote industrial innovation and economic growth better than single industrial structure). Porter spillover (industry competition and the survival of the fittest promote the knowledge innovation and economic growth). They represent industry specialization, diversification and competitive spillover, and represented by SPEC, DIV and COMP. The theoretical model of industrial knowledge spillover effects can be obtained based on the hierarchically spatial lagged dependent variable and the spatial autoregressive error (HSARAR) model. 


$$
\left\{\begin{array}{l}
\ln y_{i j t}=\lambda \sum_{g=1}^{N} \sum_{h=1}^{m_{g}} \omega_{i j, g h} y_{g h t}+\beta_{1} \ln L_{i j t}+\beta_{2} \ln K_{i j t}+\beta_{3} \ln S P E C_{i j t}+\beta_{4} \ln D I V_{i j t}+\beta_{5} \ln C O M P_{i j t}+u_{i j t} \\
u_{i j t}=\rho \sum_{g=1}^{N} \sum_{h=1}^{m_{g}} \omega_{i j, g h} u_{g h t}+\varepsilon_{i j t} \\
\varepsilon_{i j t}=\alpha_{i}+\mu_{i j}+v_{i j t}
\end{array}\right.
$$

Where $y_{i j t}$ is the industry value added of the " $t$ th time period $-i$ th region $-j$ th industry", to measure the industry development. $L_{i j t}, K_{i j t}, S P E C_{i j t}, D I V_{i j t}, C O M P_{i j t}$ is the independent variables of the " $t$ year $-t$ region $-j$ industry". All variables are summarizing in Table $1 . \lambda$ is the scalar spatial lag coefficient with $|\lambda|<1 . \rho$ is the scalar spatial autoregressive error coefficient that captures the strengthen of spatial error correlation with $|\rho|<1 . \omega_{i j, g h}$ is the element of spatial weights matrix with $i j$ denotes the relation of industry $j$ within region $i$ and similarly for $g h$, $\omega_{i j, g h}$ is specified by the contiguity criterion, with $\omega_{i j, g h}=1$ if industry $j$ within region $i$ and industry $h$ within region $g$ share a same border and $\omega_{i j, g h}=0$ otherwise. $u_{i j t}$ is the error term of the " $t$ year $-t$ region $-j$ industry", which is spatially correlated with $\varepsilon_{i j t}$ further decomposed into three component $\alpha_{i}, \mu_{i j}$, and $v_{i j t} . \alpha_{i}$ is the $i$ th region-level random effects. $\mu_{i j}$ is the nested industry-level random effects of the $j$ th industry within the $i$ th region. $v_{i j t}$ is the innovation vector.

Table 1: Variables and Description

\begin{tabular}{|l|l|l|l|l|}
\hline Parameter & Variable & $\begin{array}{c}\text { Variable } \\
\text { implication }\end{array}$ & $\begin{array}{c}\text { Expected } \\
\text { symbol }\end{array}$ & \multicolumn{1}{|c|}{ Economic meaning } \\
\hline$\beta_{1}$ & $\ln L$ & Labour inputs & + & Labour promote economic growth \\
\hline$\beta_{2}$ & $\ln K$ & Capital inputs & + & Capital promote economic growth \\
\hline$\beta_{3}$ & $\ln S P E C$ & MAR spillover & + & $\begin{array}{l}\text { MAR spillover, specialized industry } \\
\text { promote economic growth }\end{array}$ \\
\hline$\beta_{4}$ & $\ln D I V$ & $\begin{array}{l}\text { Jacobs } \\
\text { spillover }\end{array}$ & + & $\begin{array}{l}\text { Jacobs spillover, diversification } \\
\text { industrial structure promote } \\
\text { economic growth industry }\end{array}$ \\
\hline$\beta_{5}$ & $\ln C O M P$ & Porter spillover & + & $\begin{array}{l}\text { Porter spillover, ponomic } \\
\text { competition promote econom } \\
\text { growth }\end{array}$ \\
\hline
\end{tabular}

The specialized indicator (MAR spillover) $S P E C_{i j t}$ is calculated by the method of Batisse (2002) and Mihn (2004). The diversification indicator (Jacobs spillover) $D I V_{i j t}$ is calculated according to the method of Ellison and Glaeser (1997). The industry competition (Porter spillover) COMP based on the method of De Lucio et al. (2002). The proportion of industry value added, employees, or enterprises to nation, are used to capture knowledge spillover effect. 


\section{Estimation Results of the HSARAR Model}

The pooled regression model and SARAR panel data model in our empirical research are used to compare to HSARAR model. In terms of pooled regression model, the variable value will be marked "null" when there is no corresponding industry, and we employ OLS to estimate the parameters. For SARAR model, we use the GMM estimators for the spatial autoregressive error coefficient and standard deviation of the error term, then the regression parameters are estimated by IV estimation. With regard to HSARAR model, we use GMM estimation to estimate the spatial autoregressive error coefficient and standard deviation of the error term, then the regression parameters are estimated by FGLS estimation. All the calculations are running in GAUSS 15.0. The results are stated in Table 2.

Table 2: Estimation Results of the Models for Industrial Knowledge Spillover Effects

\begin{tabular}{|l|l|l|l|}
\hline Parameter & Pooled Model $^{1}$ & SARAR Model & HSARAR Model \\
\hline$\beta_{1}$ & $0.1767^{* * *}$ & $0.4233^{* * *}$ & $0.3977^{* * *}$ \\
\hline s.e. & $(0.0055)$ & $(0.0134)$ & $(0.0131)$ \\
\hline$\beta_{2}$ & $0.8188^{* * *}$ & $0.5932^{* * *}$ & $0.6051^{* * *}$ \\
\hline s.e. & $(0.0053)$ & $(0.0123)$ & $(0.0120)$ \\
\hline$\beta_{3}$ & $0.0110^{* * *}$ & $0.1191^{* * *}$ & $0.1099^{* * *}$ \\
\hline s.e. & $(0.0016)$ & $(0.0066)$ & $(0.0064)$ \\
\hline$\beta_{4}$ & 0.0012 & $0.0268^{* * *}$ & $0.0216^{* * *}$ \\
\hline s.e. & $(0.0014)$ & $(0.0076)$ & $(0.0092)$ \\
\hline$\beta_{5}$ & $0.0122^{* * *}$ & $0.0276^{* * *}$ & $0.0246^{* * *}$ \\
\hline s.e. & $(0.0018)$ & $(0.0042)$ & $(0.0041)$ \\
\hline$\lambda$ & -- & $0.1396^{* * *}$ & $0.1568^{* * *}$ \\
\hline s.e. & -- & $(0.0094)$ & $(0.0093)$ \\
\hline$\rho$ & -- & $0.2418^{* * *}$ & $0.2224^{* * *}$ \\
\hline s.e. & -- & $(0.0153)$ & $(0.0152)$ \\
\hline$\sigma_{\alpha}$ & -- & -- & 0.1224 \\
\hline$\sigma_{\mu}$ & -- & 0.2138 & 0.1733 \\
\hline$\sigma_{v}$ & 0.1014 & 0.1885 & 0.1889 \\
\hline
\end{tabular}

Note: ${ }^{* * *}$ is significant at $1 \%$ confidence level, ${ }^{* *}$ is significant at $5 \%$ confidence level, ${ }^{*}$ is significant at $10 \%$ confidence level.

The pooled regression model empirical results imply that labor input, capital input, and knowledge spillover effect can promote economic growth. The OLS estimators support that the capital input elasticity (0.8188) is larger than labor input elasticity (0.1767), which suggests that Guangdong industrial development is mainly based on the capital input. However, the result is not in accordance with the facts reflected in Guangdong's economy. The parameter of $\ln D I V$ is not significant, which reveals that diversification industrial structure cannot promote economic

\footnotetext{
${ }^{1}$ Multiple collinear tests show that VIF of LnL、LnK、LnSPEC、LnDIV, and LnCOMP are 16.9963, 15.8434, $1.4391,1.1064$, and 1.8608 , respectively.
} 
growth. The other parameters are significant at $1 \%$ level. The parameter of spillover elasticity of specialization and competition are 0.0110 and 0.0122 , respectively. The results show that industrial specialization and competition have minimum impact on industry value added, which is contrary to Guangdong province's technology-intensive characteristics. The pooled regression model simply conduct regression on the nine-year Guangdong province data, variance inflation factor (VIF) of core variables, $\mathrm{LnL}$ and $\mathrm{LnK}$, are greater than 10, indicating a serious multicollinearity. Besides, the pooled regression model ignores the time span, hierarchical characteristics, and spatial spillover of data, resulting in over-fitting and unrealistic OLS estimation, and leading to the distortion of regression results.

SARAR and HSARAR models showed that all of them took time span and spatial effect into account, all the parameters were significant at $1 \%$. Labor input elasticity were 0.4233 and 0.3977 , respectively. Capital input elasticity were 0.5932 and 0.6051 , respectively. MAR spillover elasticity were 0.1191 and 0.1099 , respectively. Jacobs spillover elasticity were 0.0268 and 0.0216 , respectively. Porter spillover elasticity were 0.0268 and 0.0246 , respectively. Different from the pooled regression model, the results suggested that all variables in our empirical research can boost industry value added. They supported that MAR spillover, Jacobs spillover, Porter spillover were positive with industry value added, which was consistent with the expected economic meaning of Table 1. Labor input elasticity and three kinds of knowledge spillover elasticity were bigger, capital input elasticity was smaller than the results of the pooled regression model. It revealed that labor input and the knowledge spillovers could also promote industry value added when the models considered data spatial correlation. The inter-regional factors of labor input, capital input, industrial specialization, diversification, and competition spillover were reflected by SARAR and HSARAR models.

To assess the spatial correlation, the results indicated there were positive and statistically significant spatial lag of the prefectural industry value added and spatial error autocorrelation of the error term. The spatial lag coefficients $\lambda$ of SEARAR and HSARAR model were 0.1396 and 0.1568 , while the spatial autoregressive error coefficients $\rho$ were 0.2418 and 0.2224 , respectively. HSARAR model had considered spatial correlation and hierarchical structure of the data and obtained the greater value of $\lambda$ and the smaller value of $\rho$ than SARAR model. The labor input, capital input, and knowledge spillover effects were amended within HSARAR model.

SARAR model showed that standard deviation of random effect (volatility) $\sigma_{\mu_{j}}=0.2138$ for all industries. HSEMA model presented the value of $\sigma_{\alpha_{i}}$ and $\sigma_{\mu_{i j}}$. The standard deviation of hierarchical random effect $\sigma_{\alpha_{i}}=0.1224$, it was the measurement of region difference. The standard deviation of industry embedded random effect $\sigma_{\mu_{i j}}=0.1733$, it was the measurement of industry difference. Their value implied that the difference of region random effect and embedded random effect could be recognized. We could notice that $\sigma_{\mu_{i j}}<\sigma_{\mu_{j}}$ when considered data hierarchical structure. It revealed that industrial difference within the group $\sigma_{\mu_{i j}}$ was smaller than the whole industrial difference $\sigma_{\mu_{j}}$, which revealed that group similarity has been improved and SARAR model estimators have been amended. 


\section{Conclusions}

The empirical research of industrial knowledge spillover effect of Guangdong province, which was based on HSARAR model, confirmed that labor input, capital input, industrial specialization, diversification, and competition spillover could promote industrial development, and strong industry spatial correlation also existed. When the data contained the hierarchical structure and spatial correlation, compared to SARAR model, HSARAR model could recognize the regional difference and amend industrial difference. It is of interest to consider the geographic coordinate and spatial moving average error simultaneously for further research.

\section{Acknowledgements}

The authors acknowledge the Natural Science Foundation of Guangdong Province, China (Grant No.2015A030313216) and the Special and Innovative Project of Guangdong Education Bureau, China (Grant No.2014WTSCX001) and China Scholarship Council.

\section{References}

[1] Baltagi B.H., Fingleton B., Pirotte A. Spatial lag models with nested random effects: An instrumental variable procedure with an application to English house prices. Journal of Urban Economics, 80, 2014, 76-86.

[2] Cainelli G., Leoncini R. Externalities and long-term local industrial development: Some empirical evidence from Italy. Revue D'economie Industrielle, 90, 1999, 25-39.

[3] Cainelli G., Leoncini R., Montini A. The evolution of industrial sectors in Europe. Paper Prepared for the Nelson and Winter Conference Aalborg, 2001.

[4] Cliff A.D., Ord J.K. Spatial autocorrelation. Pion, London, 1973.

[5] Corrado L. Fingleton B. Multilevel modeling with spatial effects. University of Strathclyde, Discussion Paper, 2011, 11-05.

[6] Corrado L., Fingleton B. Where is the economics in spatial econometrics? Journal of Regional Science, 52, 2012, 210-239.

[7] Drucker J. Industrial structure and the sources of agglomeration economies: Evidence from manufacturing plant production. Growth and Change, 44, 2013, 54-91.

[8] Ejermo O. Technological diversity and Jacobs' externality hypothesis revisited. Growth and Change, 36, 2005, 167-195.

[9] Fingleton B., Le Gallo J., Pirotte A. Panel data models with spatially dependent nested random effects. Journal of Regional Science, 58, 2018, 63-80.

[10] Glaeser E.L., Kallal H.D., Scheinkman J.A., Schleifer A. Growth in cities. Journal of Political Economy, 100, 1992, 1126-1152.

[11] Goldstein H. Multilevel models for analysing social data. In Encyclopaedia of Social Research Methods. Newbury Park CA: Sage Publications, 1998.

[12] He M, Lin K.P. Testing spatial effects and random effects in a nested panel data model. Economics Letters, 135, 2015, 85-91.

[13] Henderson V., Kuncoro A., Turner M. Industrial development in cities. Journal of Political Economy, 103, 1995, 1067-1090.

[14] Kelejian H H, Prucha I R. Specification and estimation of spatial autoregressive models with autoregressive and heteroskedastic disturbances. Journal of Econometrics, 157, 2010, 53-67.

[15] Kreft I.G.G., De Leeuw J. Introducing multilevel modeling. London: SAGE, 1998.

[16] Martin P., Mayer T., Mayneris F. Spatial concentration and plant-level productivity in France. Journal of Urban Economics, 69, 2011, 182-195. 
[17] Mihn K.H. An analysis of agglomeration economies in the manufacturing sector of Korea. KIET Occasional Paper, No. 56. 2004.

[18] Widodo W., Salim R., Bloch H. Agglomeration economies and productivity growth in manufacturing industry empirical evidence from Indonesia. Economic Record, 90, 2014, 41-58.

[19] Zhang M., Wu Y. Impact of agglomeration spillover in spatial difference of innovation activities panel data analysis of China manufacturing industry. Micro Evidence on Innovation in Developing Economies Conference Papers, 2008.

*Corresponding author.

E-mail address: cynthia_yip @ 163.com 